\title{
Comparison of direct immunofluorescence and cell culture for detecting Chlamydia trachomatis
}

\author{
SALLY J FOULKES, ${ }^{*} \mathrm{R}$ DEIGHTON,* A R B FEENEY, ${ }^{*} \mathrm{~K}$ C MOHANTY, + \\ AND C W J FREEMAN‡ \\ From the Departments of *Microbiology and +Genitourinary Medicine, St Luke's Hospital, Bradford, \\ and the $\neq$ Department of Virology, Public Health Laboratory, Leeds
}

SUMMARY Conventional cell culture methods were compared with a direct immunofluorescence test (MicroTrak, Syva UK, Maidenhead, Berkshire) to detect Chlamydia trachomatis in 137 patients (126 women, 11 men) attending a sexually transmitted diseases (STD) clinic. Results obtained by the two tests agreed in $87 \cdot 6 \%$ of cases.

Of 34 positive specimens, 17 were detected by culture and fluorescence, 15 by fluorescence only, and two by culture only. The excess of specimens that were negative on culture but positive on fluorescence might be accounted for by delays in culture (up to 18 hours).

The MicroTrak test appears to be of value in peripheral hospitals that have to rely on transporting specimens to larger centres for culture.

\section{Introduction}

Since Gordon and Quan described the isolation of Chlamydia trachomatis in irradiated McCoy cells, ${ }^{\prime}$ the laboratory diagnosis of chlamydial infection of the genital tract has depended on isolating the organism in tissue culture and showing characteristic intracytoplasmic inclusions. As facilities for tissue culture tend to be available only in specialised centres, specimens may have to be stored and then transported some distance before they are cultured, factors which may adversely affect results. ${ }^{23}$

Syva have recently introduced a new direct fluorescence antibody test (MicroTrak) using fluorescein labelled monoclonal antibodies to the major outer membrane protein of $C$ trachomatis ${ }^{4}$ to detect the presence of chlamydial elementary bodies in material taken direct from patients. It is a test that is within the capabilities of most hospital laboratories and does not depend on the presence of living organisms, thus eliminating the problems associated with storing and transporting specimens.

In our laboratory in Bradford we evaluated the performance of the new test, comparing it with the existing cell culture method carried out for us at the Leeds Public Health Laboratory 15 miles away.

Address for reprints: Dr S J Foulkes, Department of Microbiology, Old Medical School, University of Leeds, Leeds

Accepted for publication 3 December 1984

\section{Patients and methods}

The study population consisted of patients presenting at the sexually transmitted disease (STD) clinic in Bradford during December 1983 and January 1984. Specimens were collected at all clinics except those held on Friday evenings, when transport was not available. We studied 11 men with nonspecific urethritis (NSU) and 126 women.

Specimens of urethral or endocervical material were collected, using cotton tipped wooden swabs to collect cervical specimens and cotton tipped aluminium swabs for urethral specimens. Two swabs were taken from each patient, and one was placed in transport medium and refrigerated at $4^{\circ} \mathrm{C}$ for periods of between two and 18 hours until transported to Leeds for culture. The second swab was streaked on to a slide in an $8 \mathrm{~mm}$ well for direct fluorescence, fixed with acetone, and stored at $4^{\circ} \mathrm{C}$ until stained.

Specimens were cultured on cyclohexamide treated McCoy cell monolayers on coverslips in universal containers. After being centrifuged at $2700 \times g$ for one hour, cultures were incubated at $37^{\circ} \mathrm{C}$ in $5 \%$ carbon dioxide for $\mathbf{4 8}$ hours. The cell layers were then fixed in methanol, stained with Giemsa, and examined with dark ground illumination for the typical inclusion bodies.

Slides for fluorescence were stained with the conjugate supplied and then examined with a fluorescence microscope using $\times 40$ objective for screening and $\times 100$ for confirmation. Slides were considered 
to be positive if they contained extracellular apple green fluorescing bodies, which appeared as pinpoints under low power and as small discs with a regular outline under high power. All other fluorescence patterns were disregarded. In accordance with the manufacturer's recommendations, a cut off point of 10 chlamydial bodies was used in declaring specimens positive. The presence of epithelial cells, which were stained red, was taken to indicate that a reasonable amount of material had been collected.

The number of chlamydial bodies seen in each slide was recorded using four groupings; more than 100 , 30-100, 20-30, and less than 20 . Slides were prepared for microscopy in batches of 20 to 25 . They were examined by two independent observers, and the manufacturer's prepared slides were used as controls.

\section{Results}

Of the 137 specimens examined in duplicate, 19 $(13.9 \%)$ were positive by cell culture and $32(23.4 \%)$ were positive by fluorescence.

Table I compares fluorescence and culture results. In $120(87 \cdot 6 \%)$ cases results of fluorescence and culture agreed. Of the 17 cases where there was disagreement, 15 were negative on culture and positive on fluorescence, and two were positive on culture and negative on fluorescence.

TABLE I Comparison of results by fluorescence and culture

\begin{tabular}{llll}
\hline & \multicolumn{3}{l}{ No (\%) of specimens from: } \\
\cline { 2 - 4 } Results & $\begin{array}{l}\text { Men } \\
(n=11)\end{array}$ & $\begin{array}{l}\text { Women } \\
(n=126)\end{array}$ & $\begin{array}{l}\text { Total } \\
(n=137)\end{array}$ \\
\hline Fluorescence and culture negative & 5 & 98 & $103(75 \cdot 2)$ \\
Fluorescence and culture positive & 3 & 14 & $17(12 \cdot 4)$ \\
Fluorescence positive, culture negative 3 & 12 & $15(10 \cdot 9)$ \\
Fluorescence negative, culture positive 0 & 2 & $2(1 \cdot 5)$ \\
Total positive by either method & 6 & 28 & $34(24 \cdot 8)$ \\
\hline
\end{tabular}

Most specimens were endocervical specimens from women patients. Only $11(8 \%)$ specimens from men (all urethral specimens) were examined.

Table II shows the number of specimens giving positive results by fluorescence and those also

TABLE II Specimens giving positive results on fluorescence and culture, grouped according to elementary bodies seen on fluorescence

\begin{tabular}{lll}
\hline & \multicolumn{2}{l}{ No $(\%)$ positive by: } \\
\cline { 2 - 3 } $\begin{array}{l}\text { No of elementary bodies } \\
\text { in fluorescence smears }\end{array}$ & $\begin{array}{l}\text { Fluorescence } \\
(n=32)\end{array}$ & $\begin{array}{l}\text { Fluorescence and } \\
\text { culture }(n=I 7)\end{array}$ \\
\hline 100 & $6(18 \cdot 8)$ & $4(23 \cdot 5)$ \\
$30-100$ & $9(28 \cdot 1)$ & $6(35 \cdot 3)$ \\
$20-30$ & $12(37 \cdot 5)$ & $6(35 \cdot 3)$ \\
$<20$ & $5(15 \cdot 6)$ & $1(5 \cdot 9)$ \\
\hline
\end{tabular}

yielding cultures, grouped according to the number of elementary bodies they contained. The number of specimens in each group was small, but showed a lower percentage of culture positive specimens in the group with small numbers of elementary bodies on fluorescence.

\section{Discussion}

The direct fluorescence test (MicroTrak) is relatively simple to perform, but interpretation of the fluorescence does require experience, as other fluorescence patterns are often seen. The test also requires a correctly set up fluorescence microscope of good quality.

We followed the manufacturer's advice in using a cut off point of 10 organisms for declaring a result positive. This number may be rather large, but was used because of the possibility of misidentifying other fluorescing bodies. Smaller numbers of chlamydial bodies should not be ignored, however, and repeat specimens should be obtained to clarify the result. The problems associated with interpreting fluorescence make the test unsuitable for performance by staff inexperienced in microbiological techniques.

The large number of culture negative, fluorescence positive specimens was disappointing, but may reflect the problems associated with delayed culture of specimens. Other workers, however, have described similar results with smaller numbers of specimens. ${ }^{56}$ Ruijs and colleagues also compared fluorescence and culture in a group of 53 men patients, and found that delayed culture gave poorer results than immediate culture, although culture generally appeared to be better than fluorescence. ${ }^{7}$ Thomas and colleagues found good correlation between the two methods in their study of 100 men with non-gonococcal urethritis and 100 men with gonorrhoea, with agreement in $99 \%$ and $94 \%$ of cases respectively. ${ }^{8}$ Their specimens for culture, however, were snap frozen in liquid nitrogen before storage and transport.

It was impossible to ascertain whether our duplicate swabs contained comparable amounts of material, and variation in the content of the specimens may account for a few of the discrepancies. The higher proportions of culture negative specimens associated with lower numbers of elementary bodies seen on fluorescence may indicate a variation in sampling and also the delay in culture, which may be more important if small numbers of elementary bodies are present in specimens.

Examination of large numbers of direct fluorescence slides is technically demanding and tedious and thus does not appear to be suitable for use in large 
clinics, where adequate facilities for culture exist. In a peripheral hospital, however, which has to rely on transport of specimens to major centres, the technique appears to be of value in the initial diagnosis of chlamydial infection.

We thank Dr M H Hambling, Department of Virology, Public Health Laboratory, Leeds, and Dr W M Edgar, Bradford Royal Infirmary, for their help and advice. We also thank Mrs J Hannay and Miss C Atkinson for secretarial help.

\section{References}

1. Gordon FB, Quan AL. Isolation of the trachoma agent in cell culture. Proc Soc Exp Biol Med 1965; 118:354-9.

2. Kallings, I, Mårdh P-A. Sampling and specimen handling in the diagnosis of genital Chlamydia trachomatis infections. Scand J Infect Dis 1982;32 suppl:21-4.
3. Tjiam KH, van Heijst BYM, de Roo JC, et al. Survival of Chlamydia trachomatis in different transport media and at different temperatures: diagnostic implications. British Journal of Venereal Diseases 1984;60:92-4.

4. Stephens RS, Tam MR, Kuo CC, Nowinski RC. Monoclonal antibodies to Chlamydia trachomatis: antibody specificities and antigen characterization. $J$ Immunol 1982; 128: 1083-9.

5. Mallinson H, Turner GC, Carey PB, Khan MH. Rapid detection of Chlamydia trachomatis with monoclonal antibodies. Lancet 1984; i: 1180-1.

6. Berron S, Vazquez J, Fenoll A. Rapid detection of Chlamydia trachomatis. Lancet 1984; ii: 109-10.

7. Ruijs G, Kraai EJ, van Voorst Vader PC, Schirm J, Schröder FP. Rapid detection with monoclonal antibodies of Chlamydia trachomatis in urethral smears and urine sediments. Lancel 1984; i:960-1.

8. Thomas BJ, Evans RT, Hawkins DA, Taylor-Robinson D. Sensitivity of detecting Chlamydia trachomatis elementary bodies in smears by use of a fluorescein labelled monoclonal antibody: comparison with conventional chlamydial isolation. $J$ Clin Pathol 1984;37:812-6. 